\title{
EL TRABAJO DEL AUTOR SOBRE SÍ MISMO: LOPE DE VEGA ESCRIBE LA NUEVA VICTORIA DE DON GONZALO DE CÓRDOBA
}

\author{
Daniele Crivellari \\ Dipartimento di Studi Umanistici \\ Università degli Studi di Salerno \\ Via Giovanni Paolo II, 132 \\ 84084 Fisciano, Salerno (Italia) \\ dcrivellari@unisa.it
}

El corpus de comedias autógrafas de Lope de Vega que ha llegado hasta nosotros constituye un patrimonio excepcional, tanto desde un punto de vista cuantitativo como cualitativo; los más de cuarenta hológrafos lopescos cubren buena parte de su carrera dramática ${ }^{1}$, y tienen un valor extraordinario como fuente de información sobre los procesos de composición, por parte del Fénix, de sus piezas. A este propósito, cabe especificar en primer lugar que estos testimonios son prácticamente todos apógrafos ${ }^{2}$ : como ha sido demostrado en varias ocasiones, y como las señales textuales ponen de manifiesto también en el caso de la comedia que aquí nos ocupa, Lope debió de pasar a limpio el texto

${ }^{1}$ Desde El favor agradecido (19.XII.1593) hasta Las bizarrías de Belisa (24.V.1634), aunque el manuscrito de La mayor virtud de un rey se situaría entre 1634 y 1635; ver Presotto, 1999.

${ }^{2}$ Sobre este aspecto pueden verse por ejemplo Presotto (en Vega, 2007, p. 1301), Gavela García (en Vega, 2008, p. 34) y Crivellari (2013a, pp. 22-26). 
a partir de un borrador, que luego destruiría o que se perdería. La falta del antígrafo, por un lado, excluye indudablemente la posibilidad de observar una parte del trabajo del autor - piénsese, por ejemplo, en la mina de datos que suponen en este sentido el Códice Daza o el DuránMasaveu $^{3}$. El hecho de que estos manuscritos fueran unos productos «definitivos» destinados a la venta a las compañías, por otro lado, conlleva una serie de cuestiones ulteriores: los textos presentan una versión que el dramaturgo en algún momento decidió despachar, a veces no sin aportar cambios radicales a una forma anterior, que él mismo había establecido previamente; en cuanto documentos oficiales, y a diferencia de los borradores, a veces las piezas muestran las huellas de las intervenciones censorias; finalmente, al tratarse de textos concebidos concretamente para el momento de su representación, están sometidos a veces a las tensiones producidas por las circunstancias de la puesta en escena, bien desde el interior de la compañía (por ejemplo por las necesidades ligadas al número de actores, las variaciones aportadas por el autor de comedias, etc.), bien por la intervención de factores que podríamos llamar contextuales, como en el caso de comedias que escenifican hechos históricos contemporáneos o que incluyen en las dramatis personae a personajes reales, que a veces podían encontrarse entre el público.

En el caso de La nueva victoria de don Gonzalo de Córdoba todos estos elementos deben ser considerados a la hora de abordar el texto autógrafo, ya que el manuscrito se nos presenta como un palimpsesto donde quedan las huellas evidentes de varios cambios — aportados en su mayoría por Lope- que pueden entenderse tan solo de tener en la debida cuenta tanto los aspectos materiales como los psicológico-contextuales de la producción de la obra. La comedia, como el mismo título sugiere, se centra principalmente en la exaltación de la figura del hermano del Duque de Sesa, Gonzalo Fernández de Córdoba y Cardona, y de su victoria en Fleurus, el 29 de agosto de 1622, contra las tropas de los protestantes capitaneadas por el bastardo Ernesto Mansfeld, hijo ilegítimo del conde Pedro Ernesto de Mansfeld, en el marco de la guerra de los Treinta Años ${ }^{4}$. La pieza, pues, se inscribe en el subgénero de las comedias genealógicas y, como tal, pretende ensalzar a un personaje y a

${ }^{3}$ Para el Códice Daza remitimos al interesante estudio de Sierra Matute, 2011.

${ }^{4}$ Sobre el contexto histórico de los personajes que aparecen en la comedia son útiles las paginas que Ziomek (1962, pp. 39-76) dedica al tema, aunque es fundamental el estudio de Usandizaga (2014, pp. 69-82); también resulta imprescindible Ferrer, 2012. 
todo un linaje; este aspecto, como veremos, debió de influir en algunas modificaciones al texto aportadas por el dramaturgo ${ }^{5}$.

El manuscrito ${ }^{6}$ de La nueva victoria está fechado «en Madrid a 8 de otubre de 1622» (fol. 15r, acto III) y lleva la aprobación del censor Pedro de Vargas Machuca del 21 de octubre del mismo año. La fecha del 8 de octubre es, claro está, la de la ultimación del manuscrito, aunque en este caso también tenemos un terminus post quem, ya que la noticia de la victoria de las tropas españolas en Fleurus, al parecer, llegó a Madrid el 19 de septiembre de 1622, como observan Menéndez Pelayo (1949, pp. 247-248) y Usandizaga (2014, p. 77). El Fénix, por tanto, dispuso de poco más de 15 días — 19, exactamente - para redactar la pieza, lo cual permite hacer unas hipótesis concretas sobre sus tiempos de composición, sobre todo si consideramos que el texto que nos ha llegado es una copia de un borrador. Sin embargo, es posible asimismo que Lope pudiera volver marginalmente sobre lo ya escrito en los días sucesivos, es decir, antes de entregar el pliego al censor o antes de la primera representación ${ }^{7}$, que corrió a cargo de la compañía de Juan Bautista

${ }^{5}$ Junto al argumento principal, además, Lope desarrolla una trama paralela, la historia del soldado Juan Ramírez y su amor por una dama, Lisarda, que Ferrer (2001, p. 20) resume así: «en La nueva victoria de don Gonzalo de Córdoba Lope se saca de la manga una historia de amor secundaria entre Juan Ramírez, soldado al servicio de don Gonzalo, y Lisarda. No obstante, llegado el momento de pelear, y puesto por Lisarda ante la tesitura de tener que elegir entre ella y la guerra, el héroe decidirá abandonarla, aun cuando se reencuentren, sin mediar enredo, tras el lapso bélico, al finalizar la comedia». Es de notar que Juan pertenece a la familia de los Vargas (es «caballero de los Vargas de esta corte», v. 820+), lo cual implica que pudiera haber cierto interés en Lope por halagar también a esta familia.

${ }^{6}$ BNE, sign. Res/84. En la página de la Biblioteca Digital Hispánica (<www.bne. es/es/Catalogos/BibliotecaDigital $>$ ) se encuentra una reproducción digital del manuscrito. Para una descripción detallada del texto remitimos al estudio de Presotto (2000, pp. 292-298). En la indicación de los folios, seguiremos la numeración original de Lope, que vuelve a empezar en cada acto, señalando por tanto en cada caso la jornada correspondiente. Para las citas del texto, seguimos la edición a cargo de Ziomek (1962), la única disponible hasta la fecha, aunque intervenimos en la puntuación, subsanando errores y lagunas.

${ }^{7}$ Según Usandizaga (2014, p. 77), «probablemente el estreno tuvo lugar en Madrid, donde el autor [Juan Bautista] y su mujer, la actriz Manuela Enríquez, se encontraban el 12 de noviembre». 
Almella, llamado Valenciano, e incluyó a Cosme Pérez, Juan Rana, entre los representantes.

En efecto, lejos ya de la imagen algo romántica de un dramaturgo que compone a vuela pluma los versos de sus comedias ${ }^{9}$, el manuscrito de La nueva victoria presenta signos inequívocos que demuestran que el texto es fruto de un proceso de autocopia. Prueba de ello son los múltiples errores por haplografia, duplografia y los saltos por homoioteleuton: en el fol. $1 \mathrm{r}$ del tercer acto, por ejemplo, Lope repite dos veces el error "querme», por "quererme», que corrige en un segundo momento en el interlineado. Por lo que atañe a los casos de duplografia, en el primer acto (fol. 9r) el dramaturgo empieza el folio con el verso «en la jerigonza nueva», que luego tacha para copiarlo en el lugar correcto, tres versos más abajo (v. 501). Análogamente, en el fol. 6v la primera palabra de la intervención de Lisarda en el ámbito de un verso partido, "cómo", ha sido copiada inicialmente antes de la indicación de su nombre como interlocutor, a continuación de la frase anterior, pronunciada por Fulgencia; esto delata un error en el paso de la memorización de la perícopa a la redacción de la misma, error inmediatamente subsanado por el autor, que tacha el primer "cómo", introduce la abreviación del nombre de Lisarda, y continúa la redacción. Finalmente, resultan muy interesantes las trazas de posibles errores debidos a saltos por homoioteleuton, ya que permiten confirmar sin lugar a dudas que el manuscrito es el producto de una operación de autocopia. Nos parece paradigmático, en este sentido, el caso del v. 864, en el primer acto (fol. 15r): aquí Lope escribe "pues ese tu nombre de sea», tachando luego la penúltima palabra. El error, subsanado enseguida, se explica de observar que poco más abajo (v. 866) se encuentra el verso "y por ser nombre de dueña»: no es dificil suponer que el dramaturgo incurriera en el error debido a la repetición, en el espacio reducido de tres versos, de un mismo sustantivo («nombre»).

Una vez establecido el carácter de copia del manuscrito, los aspectos más interesantes por analizar son los que pueden arrojar luz nueva sobre los procesos de composición de la pieza. Estos incluyen, naturalmente, también la corrección de los errores que Lope encuentra en el borra-

${ }^{8}$ Ver Ziomek (1962, pp. 95-96), Presotto (2000, p. 295), Ferrer Valls (2002, p. 140) y la bibliografia allí citada.

${ }^{9}$ Menéndez Pelayo (1949, p. 248) habla, a propósito de esta pieza, de su «versificación tan fácil y tan improvisada como improvisada fue la victoria del novicio capitán». 
dor o los que produce en el acto de la copia, pero atañen más específicamente a los planos tanto formal como estructural del texto, con cambios in itinere que van desde modificaciones que podríamos llamar genéricamente «estilísticas» hasta aquellas de más envergadura, que llegan incluso a un replanteamiento del desarrollo de la acción dramática en algunas escenas. A este propósito, nos centraremos en primer lugar en las intervenciones del poeta de comedias, pasando luego a las modificaciones - una, concretamente- atribuibles al autor de comedias ${ }^{10}$. Por cuestiones de espacio, no consideraremos aquí los casos en los que Lope aporta cambios por razones estilísticas, con intervenciones destinadas a evitar la repetición de un término en un mismo verso o en el espacio reducido de pocos versos. Estas reiteraciones, que el dramaturgo notaría en el momento de la copia, suelen ser corregidas en el acto, mayormente por medio de la tachadura de una palabra y la sustitución con un sinónimo u otro vocablo, al lado o en el interlineado. Tampoco nos detendremos en las modificaciones que corrigen hipermetrías de los versos o errores ligados a la rima, así como en aquellos casos en los que el Fénix introdujo cambios para concretar el sentido de unos parlamentos o agilizar la comprensión del texto por parte del público, modificando unas estructuras frasales o unas referencias que debieron de parecerle demasiado difíciles. Sí, en cambio, nos centraremos en los loci que indican que Lope advirtió en algunos momentos la necesidad de reorganizar la estructura de algunas escenas, reescribiendo fragmentos o añadiendo ex novo porciones de texto. El análisis de estos casos permite observar cómo el comediógrafo plasmaba el material dramático no solo basándose en sus propias exigencias como autor, sino considerando también el contexto de la representación.

En el manuscrito de La nueva victoria hay varios casos interesantes a este respecto: el primero que comentaremos es el que se encuentra hacia el final de la primera jornada, y más específicamente en el fol. 15v (imagen 1). La escena que se está desarrollando es la del primer encuentro entre don Juan y Gonzalo de Córdoba; después de leer este último la carta con la que su hermano, el duque de Sesa, le habla de Juan, la atención del protagonista se fija en su lacayo, Bernabé. El gracioso se presenta de manera burlesca, explicando los supuestos e irónicos

10 También sería interesante observar la relación que se establece entre el manuscrito, sus modificaciones y la versión del texto que pasó a la imprenta en la primera edición de la pieza, en la Vega del Parnaso (1637). 
orígenes del nombre de su pueblo, Caramanchel. Tras esto, Bernabé se ofrece para combatir a los protestantes dejándolos sin abastecimientos, ya que - afirma - se comerá todo lo que hay en dos semanas y media. Originariamente, después de la cómica propuesta del lacayo, Lope escribió 7 versos en los que Gonzalo y el capitán Ibarra volvían a centrarse en el inminente ataque a Mansfeld, más una acotación («Váyanse, y queden don Juan y Bernabé», v. 934+). Acto seguido, sin embargo, el dramaturgo decidió dilatar la escena, alargando el momento cómico del diálogo entre Gonzalo y el lacayo; por tanto, tachó el pasaje y añadió una parte nueva, prosiguiendo con el romance en é-a por 26 versos más antes de volver a copiar las intervenciones de Gonzalo e Ibarra y la didascalia (fol. 16r, imagen 2). Es de excluir que los versos tachados fueran transcritos en el fol. 15v por error; en primer lugar, es improbable que Lope se extendiera tanto en la copia del texto antes de percatarse de una omisión tan evidente. En segundo lugar, casos análogos se encuentran en otros autógrafos del Fénix ${ }^{11}$, constituyendo una prueba fehaciente de la habilidad con la que el dramaturgo plasmaba in itinere la materia poética y su capacidad de modificar sobre la marcha el desarrollo de la acción dramática.

Los versos añadidos, por un lado, representan un paréntesis cómico ulterior y guiñan el ojo a los espectadores, ya que el diálogo de Bernabé y Gonzalo versa sobre temas tan trillados en las comedias como los coches de Madrid, sus «tres mil tiendas» (v. 905), además de la moda. Por otro lado, el añadido contribuye a presentar a don Gonzalo no sólo como un personaje hábil y valeroso a nivel militar, sino también como hombre de buen humor, dispuesto a mantener una divertida charla con el gracioso sobre las costumbres de la capital. Desde esta perspectiva, también la intervención del protagonista de los vv. 929-930 ("Ahora bien, esto se queda / para tiempo de más gusto»), que originariamente se encontraba después del v. 901, adquiere un significado distinto, dado que se refiere no ya tan solo a una boutade - la propuesta de Bernabé de sustraer los víveres al enemigo-, sino en sentido más amplio a toda la conversación de carácter cómico mantenida con el lacayo ${ }^{12}$. Téngase en

11 Ver, por poner sólo un ejemplo, el caso de El piadoso aragonés, cuyo manuscrito analizamos recientemente (Crivellari, 2013b).

12 Además, como observa Usandizaga (2014, pp. 87-88), la conversación de Gonzalo con Bernabé sobre estos asuntos es un elemento característico de la orientación populista de la comedia. 
cuenta que el objetivo principal de la pieza es el de ensalzar la figura de Gonzalo a nivel militar y humano.

Además de este primer ejemplo, como se ha dicho, se encuentran en el manuscrito de La nueva victoria otras modificaciones que constituyen señales evidentes de que Lope sintió la necesidad de volver a posteriori sobre su propio texto. En concreto, hay dos fragmentos (de 16 y 8 versos, respectivamente) añadidos en los últimos folios, entre la firma con rúbrica del autor y la aprobación del censor, más una pequeña hoja que ha sido insertada entre los fols. $9 \mathrm{v}-10 \mathrm{r}$ del tercer acto. La modalidad con que el Fénix interviene es inusual, como observó ya Presotto (2000, p. 296), pero permite establecer sin lugar a dudas que se trata de cambios introducidos en un segundo momento respecto a la redacción definitiva del texto. El primer fragmento, constituido por dos octavas reales, está

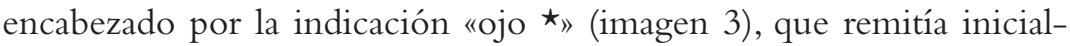
mente a la misma llamada después del v. 2146 (fol. 6v, acto III), aunque posteriormente su colocación fue variada, como veremos. El segundo fragmento, en cambio, presenta la indicación «ojo +» (imagen 4), y se compone de ocho versos en romance; esta porción de texto debería insertarse entre los vv. 1544-1545, como indicó el mismo dramaturgo por medio de una línea en el fol.10v de la segunda jornada. El orden de los dos fragmentos en los últimos folios del manuscrito, pues, demuestra que Lope decidió incorporar antes el pasaje del tercer acto y luego el del segundo.

Empezando por este último, la escena en la que se inserta el fragmento añadido se desarrolla en Flandes, y prevé la presencia en el tablado de don Gonzalo, el barón de Tili y el maestre de campo Francisco de Ibarra. El protagonista, tras hablar de una relación que escribió al rey para informarlo sobre los sucesos de la primera campaña militar (la batalla de Wimpfen), anuncia su intención de redactar otra, para ponerlo al día sobre «los valientes hechos / que hicieron en su servicio / españoles y flamencos» (vv. 1500-1502) en la batalla de Höchst. La finalidad de la guerra, añade, es poner freno al avance de los protestantes y garantizar el control del imperio castellano sobre Europa y el norte de África; a este propósito, Gonzalo enumera algunas plazas estratégicas y el noble que las rige: Milán, gobernada por el duque de Feria (Gómez IV Suárez de Figueroa), Orán por Jorge de Cárdenas Manrique de Lara y Nápoles por el duque de Alba. Es de notar que con relación a este último personaje, el archiconocido mecenas de Lope, se anuncia su inminente nombramiento como virrey («dícese que viene el de Alba / a Nápoles», 
vv. 1551-1552), cargo que efectivamente el duque ocuparía a partir del mes de diciembre de 1622. En el ámbito de esta «geografia de alabanzas», el Fénix debió de considerar oportuno ampliar la intervención de Gonzalo con dos referencias más, para nada casuales:
El príncipe de la mar, el heroico Filiberto, cumple bien la obligación de ser de Felipe nieto; el marqués de Santa + [Cruz] asombra el Asia corriendo con sus galeras las costas, con su fama tierra y cielo.

El «heroico Filiberto» es seguramente Manuel Filiberto de Saboya (1588-1624), virrey de Sicilia y, efectivamente, nieto de Felipe II por parte de madre, siendo hijo de Catalina de Austria ${ }^{13}$. En cuanto al marqués de Santa Cruz, Álvaro de Bazán (1571-1646), se trataba de un personaje querido por Lope, que lo exalta también en Servir a señor discreto y, naturalmente, en La nueva victoria del Marqués de Santa Cruz, además de dedicarle varias composiciones y aludir a él en innumerables ocasiones ${ }^{14}$. Como se puede ver, en este caso la añadidura no modifica radicalmente la estructura de la escena, aunque sí es muy interesante por hablarnos de las posibles presiones sobre el dramaturgo en lo referido a lo que antes definimos el «factor contextual». De hecho, además de la evidentísima finalidad encomiástica de la comedia respecto a Gonzalo de Córdoba, a través de estos versos Lope quería sin duda agasajar también a los personajes mencionados.

Tanto el segundo fragmento añadido al final del manuscrito como la pequeña hoja insertada entre dos folios amplían unas escenas del tercer acto. A este propósito, es importante examinar las distintas secuencias que se suceden en esta jornada y observar el desarrollo de la acción para entender si —y cómo- los cambios afectan a la estructura de la pieza.

${ }^{13}$ No nos parece verosímil la atribución de Ziomek (1962, p. 73) a otro Manuel Filiberto, gobernador de los Páses Bajos entre 1555 y 1559, nacido en 1528 y fallecido en 1580. Tampoco nos parece acertado que el Álvaro de Bazán al que alude Lope sea el primer marqués de Santa Cruz, que había fallecido en 1588, sino que se trata más bien del segundo (Álvaro de Bazán y Benavides).

${ }^{14}$ VerVega, 1994, p. 282. 
En este acto, llegando el momento más álgido del argumento, Lope presenta el estallido de la guerra entre cristianos y protestantes desde varios puntos de vista: en primer lugar, escenificando la preparación del ataque por parte de Gonzalo y sus tropas (vv. 1983-2098); en segundo lugar, representando a Mansfeld mientras observa cómo sus huestes son derrotadas (vv. 2099-2146); y, en tercer lugar, llevando a las tablas un episodio específico y de alguna manera más «íntimo» de la batalla, esto es, el enfrentamiento de Bernabé con un soldado flamenco, más el reencuentro y la reconciliación entre Juan y Lisarda, que ha seguido a su amado hasta Flandes disfrazada de hombre (vv. 2147-2352). Las voces de victoria que Juan y Bernabé escuchan en este cuadro (vv. 2166-2167) se concretan en el siguiente, donde el barón de Tili anuncia que Mansfeld ha huido a Lieja y todos dan voces para celebrar el triunfo (vv. 2353-2368).

Ahora bien, analizando en primer lugar el añadido entre los fols. 9v-10r, en este caso Lope no indica con precisión el punto a partir del cual hay que insertar el nuevo fragmento; sin embargo, la posición de la hoja, la métrica y la repetición de los primeros dos versos ( $«$ Ea, soldados valientes, / no quede vida en el campo!») y de los últimos tres ( «iVengad los muertos amigos / y el mayor q[ue] me ha faltado / en don Fran[cis] co de Ibarra!») no deja lugar a dudas sobre su correcta colocación. Así, los cinco versos de la primera versión se triplican, convirtiéndose en una tirada más larga de 15 versos. A nivel del contenido, Lope inserta $e x$ novo una exhortación de Gonzalo de Córdoba a un "gallardo español» para que tome parte valerosamente en la batalla:

¡Ea, soldados valientes, no quede vida en el campo! ¡Ea, gallardo español, valeroso don Fernando de Silva, cuyo valor, cuyo esfuerzo, cuyo brazo, cuyas famosas hazañas dignas de Hé[c]tor y Alejandro hoy nos han dado vitoria, ganad la corona y lauro de valiente capitán, que os mira Felipe Cuarto! ¡Vengad los muertos amigos y el mayor que me ha faltado en don Fran[cis]co de Ibarra! 
Cabe preguntarse, claro está, quién era Fernando de Silva, y por qué Lope insertó a posteriori estos versos en alabanza de dicho personaje. No hemos podido encontrar una figura con este nombre de cuya presencia quedara constancia en las cartas, relaciones de sucesos y otros documentos relativos a la batalla de Fleurus ${ }^{15}$. En la Relación hecha por don Gonzalo Fernández de Córdoba de la batalla de Flerus, ocurrida en 29 de agosto de 1622, sin embargo, se encuentra una referencia a «la buena resolución de don Felipe de Silva, hermano del conde de Portalegre, que gobierna la caballería y embistió con muy poca a la mitad de la del enemigo, atropellándola bravamente», y gracias al cual, afirma Gonzalo, «pusimos las cosas en muy buen estado, y les matamos gran cantidad de gente con la artillería y mosquetería, quitándoles gran cantidad de estandartes y algunas banderas, y obligándoles a que nos dejasen el puesto y se retirasen» (CODOIN, 1869, p. 308). Es de notar que Felipe de Silva es el único soldado del que Gonzalo menciona explícitamente el nombre al relatar el desarrollo de la batalla. Ahora bien, ¿pudo Lope leer la relación del hermano de su mecenas, enterándose así de la importancia estratégica de la acción de este noble? Sea como fuere, lo cierto es que si el Fénix quería referirse al hermano del conde de Portalegre, se equivocó al transcribir su nombre ${ }^{16}$, un nombre que, además, no debió de parecer el más adecuado, dado que fue tachado y sustituido por otro, el

15 Tenemos constancia de dos Fernando de Silva, respectivamente cuarto y sexto conde de Cifuentes, que vivieron en el siglo Xvi (Ávila Seoane, 2006, pp. 422-425), pero podría tratarse simplemente de homónimos del personaje al que hace referencia Lope; además, no parece verosímil que el Fénix introdujera a un noble muerto más de treinta años atrás entre tanta figura contemporánea e históricamente documentada. Otro Fernando de Silva, este sí activo en los años veinte del Seiscientos, en 1622 estaba empeñado en una batalla contra los holandeses para la conquista de Macao, y no gozó de mucha popularidad en la historia española debido a un acto semi-pirático que emprendió en agosto de 1624 (Rodao García, 1997, pp. 50-51). Tampoco nos parece posible que Lope se refiriera a Fernando de Silva y Mendoza, más conocido como Fray Pedro González de Mendoza, que por aquel entonces era arzobispo de Zaragoza y sería obispo de Sigüenza a partir de 1623. En los documentos relativos a la Jornada que realizó Felipe III en 1619 a Lisboa, aparece entre los acompañantes un Fernando de Silva, «regidor» (Labrador Arroyo, 2006, p. 273), sobre el cual sin embargo no tenemos más datos.

${ }^{16} \mathrm{El}$ nombre «Felipe», por otra parte, no hubiera permitido respetar la asonancia del romance en á-o. 
de Álvaro Losada ${ }^{17}$. Podemos afirmar con cierta seguridad que la modificación fue aportada en un momento sucesivo respecto a la redacción del añadido, ya que la tinta es diferente, aunque la mano es indudablemente de Lope.

Teniendo en cuenta, como señala Usandizaga (2014, pp. 96-97), «la alta probabilidad de que La nueva victoria de don Gonzalo de Córdoba haya surgido de un encargo de la familia del protagonista al secretario del duque de Sesa» ${ }^{18}$, nuestra impresión es que la modificación del nombre con el de Losada pudiera haberla realizado el Fénix por voluntad de algún familiar del de Córdoba, y de todos modos con el objetivo de hacer aparecer en la pieza un "muy íntimo amigo» —así lo define el mismo Gonzalo (CODOIN, 1869, p. 326) - del protagonista. Este dato adquiere aún más significado si se considera que Losada intervino activamente en el proceso de solicitud al rey, por parte de Gonzalo, para el reconocimiento de sus méritos, y que a principios de diciembre de 1622 se encontraba en Madrid «para colaborar con Fernando [...] en las gestiones ante los ministros de Felipe IV para mejorar la situación de su superior» (Usandizaga, 2014, p. 81) ${ }^{19}$.

Otra vez, pues, el contexto de la producción de la obra resulta imprescindible para entender el proceso de composición y las tensiones a las que Lope estaba expuesto a la hora de concebir y redactar una pieza. Volviendo ahora a los fragmentos añadidos al final del manuscrito, en el fol. $15 \mathrm{v}$ del tercer acto se encuentran dos octavas que Lope quiso insertar después del v. 2146, como se ha comentado. En realidad, la indicación «ojo $\star_{»}$ que se halla al lado izquierdo de este verso ha sido tachada, y se ha vuelto a copiar dos folios antes, tras el v. 2098 (imagen 5). El cotejo muestra de manera inequívoca que la diferente colocación del fragmento no se debe a la mano del dramaturgo: como se aprecia en las imágenes, la realización de la jota es totalmente distinta en los dos casos, además de ser diferentes el ductus y la tinta empleada.

${ }^{17}$ En su edición de la pieza, Ziomek (1962, pp. 14-15) atribuye el fragmento añadido a un «impressario», además de no señalar que el nombre de Fernando está tachado; al manejar tan solo el microfilme del manuscrito, tampoco puede interpretar correctamente el apellido De Silva, modificado en Losada.

${ }^{18}$ Ver también Ferrer Valls, 2008, especialmente las pp. 125-134.

${ }^{19} \mathrm{Al}$ respecto puede verse la carta que Gonzalo escribió el 6 de noviembre de 1622 a su hermano el duque para anunciarle la inminente llegada de Álvaro Losada a Madrid (CODOIN, 1869, pp. 325-326). 
Como hemos anticipado, Lope divide el núcleo central del acto - la escenificación de la batalla de Fleurus - en cuatro cuadros, presentando los acontecimientos desde puntos de vista distintos: el de Gonzalo, el de Mansfeld y, finalmente, el de Juan y Bernabé, para terminar con una pequeña cola en la que, de manera circular, vuelve a aparecer en el tablado el protagonista celebrando la victoria. En concreto, después del primer cuadro - en el que el capitán español anima a sus soldados a emprender valientemente la batalla-, es en el segundo donde Mansfeld, por medio de la técnica ticoscópica, describe lo que está pasando fuera del tablado. Acto seguido, aparece su fiel compañero, Cristiano de Holstad, anunciando la inminente derrota. En este punto, y antes del comienzo de la escena protagonizada por Juan y su lacayo, se encontraba la indicación "ojo *» que fue tachada. El fragmento añadido preveía la salida al escenario de Francisco de Ibarra quien, herido de muerte, pronunciaba las siguientes palabras antes de fallecer:

\author{
¡Ea, soldados fuertes!, que aun herido \\ os tengo de animar, hasta que el alma \\ deje el pecho animoso en que ha vivido. \\ ¡Jesús, Jesús, la sangre me desalma! \\ Con mis obligaciones he cumplido, \\ que la mayor vitoria, lauro y palma \\ es morir un honrado caballero \\ sirviendo a Dios y al Rey. JJesús, yo muero! \\ La causa de la Iglesia y el servicio \\ de Filipe merecen justamente \\ la vida que les doy en sacrificio \\ a ellos. ¡Mueran! ¡Ay, valor, detente! \\ El brazo solo falta al ejercicio \\ de las armas, no el ánimo valiente. \\ Hoy en Flandes seréis, campos estraños, \\ fama y sepulcro de mis verdes años.
}

Como se ve, una vez más el añadido tiene la finalidad de poner el foco de la atención sobre un personaje concreto, exaltándolo, y subrayando tanto el trágico número de vidas que causó la guerra como la estoica voluntad de los españoles de servir a Dios y al monarca; todo ello, además, le permite a Lope ensalzar indirectamente la empresa militar del de Córdoba. Desde el punto de vista de la acción dramática, el momento del fallecimiento de Ibarra se insertaba originalmente des- 
pués de la escena protagonizada por Mansfeld, es decir, después de llevar al tablado - aunque tan solo a través de las palabras - el combate entre cristianos y protestantes, y poco antes de su conclusión. No es superfluo recordar aquí que el estallido de la guerra se produce exactamente entre el primer cuadro y el segundo (la acotación del v. 2098+ dice: «Toquen cajas, y disparen dentro algunos tiros, fingiéndose la guerra, y salga el bastardo»); y es que la anticipación de la escena de la muerte de Ibarra modifica de manera radical el equilibrio estructural del momento más importante de toda la pieza. De hecho, el desplazamiento - operado verosímilmente por el autor de comedias o por algún integrante de la compañía - hace que el capitán aparezca en el tablado y muera nada más terminar don Gonzalo su arenga a los soldados y, de facto, antes del comienzo mismo de la batalla ${ }^{20}$.

El cambio, por un lado, quitaría al personaje de Ibarra esa capa de heroicidad que seguramente Lope quería atribuirle a través del añadido, ya que se produce cierta incongruencia al fallecer el personaje antes que Mansfeld vea la derrota de sus soldados. Por otro lado, la modificación debe entenderse en relación con la única otra intervención del autor de comedias en el manuscrito ${ }^{21}$, que no casualmente se encuentra en el mismo lugar que la indicación «ojo *» de Lope, en el fol. 6v. Como puede verse en la imagen 6 , la escena entera del enfrentamiento entre el gracioso Bernabé y un soldado flamenco (vv. 2147-2166) ha sido enjaulada y borrada con unos trazos verticales. Las razones posibles de esta tachadura son varias: en primer lugar, es probable que se quisiera expurgar la única escena cómica en el ámbito de un momento tan tenso y central, el de la guerra, que constituye el nudo argumental de la pieza. Además, en sus intervenciones, el lacayo muestra estar interesado sólo en el dinero y para nada en la guerra y en la victoria del cristianismo y de España.

20 También observaremos que así se interrumpe la continuidad que Lope quiso establecer entre el final de la escena protagonizada por Gonzalo ( $¡ E a$, españoles, que Filipe os mira!», v. 2098) y el comienzo de la sucesiva, ya que el primer verso pronunciado por Mansfeld es: «iEa, mis valerosos alemanes» (v. 2099).

${ }^{21}$ Se observan, en realidad, otras pequeñas intervenciones del autor de comedias en los fols. $2 \mathrm{v}$ y $5 \mathrm{v}$ (segundo acto) y $4 \mathrm{r}$ (tercer acto), pero ninguna de ellas es una tachadura; se trata, respectivamente, de la inserción de unos paréntesis para entender mejor el sentido de una frase, de la repetición de una didascalia poco visible en el manuscrito y de la añadidura de una acotación («tocan») implícita en el texto. 
Otra vez, sin embargo, y amén de las explicaciones sobre los porqués de la tachadura, es importante observar cómo se modifica de manera sustancial el equilibrio de los cuadros: entre los versos borrados, de hecho, también se encontraba la primera intervención de Juan («Ya nos van dejando el campo», v. 2162), que establecía una relación directa con la escena anterior. Después de dejar el escenario Mansfeld y sus compañeros, pues, los espectadores de la época no asistirían al duelo de Bernabé y a la llegada de Juan anunciando el desarrollo de la batalla, como había previsto Lope, sino que oirían directamente y un tanto ex abrupto las voces «dentro" de los cristianos gritando por la victoria. Dicho en otros términos, también esta segunda intervención del autor de comedias desvirtúa el intento original del dramaturgo y remodela la estructura de la pieza respecto a lo que el autógrafo nos consigna.

El estudio de la estratificación de distintas fases y manos en el proceso compositivo de la comedia, en conclusión, ofrece un interesante testimonio de la gestación y de la vida — a veces dificultosas - del manuscrito. Aunque a veces no sea posible determinar con certeza absoluta la cronología de las modificaciones aportadas, sí es posible apreciar por un lado la cantidad y la calidad de los cambios hechos in itinere por el dramaturgo en la redacción definitiva y en los momentos anteriores a la entrega al censor; por otro lado, se puede observar la metamorfosis de la obra en su camino hacia la representación. Examinando las intervenciones operadas sobre el texto, tenemos la posibilidad de establecer las modalidades de los cambios y, a veces, llegar a hipótesis o conclusiones sobre las razones de los mismos. A propósito de este último aspecto, en lo referido a La nueva victoria, es evidente el papel que debió de jugar el factor contextual (esto es, la finalidad encomiástica de la victoria de Gonzalo de Córdoba y la función de la pieza en el proceso de solicitud de la recompensa por sus servicios a la corona) primariamente en la redacción de la obra, pero secundariamente también en los cambios que hemos analizado. De ampliar el abanico de casos estudiados, será posible entender mucho más un aspecto tan fundamental como lo es el modus operandi de Lope en la composición de sus comedias y, en definitiva, algo más de ese lento e interminable trabajo del autor sobre sí mismo. 


\section{BiBLIOGRAFÍA}

Ávila SeoAne, Nicolás, «El señorío de los Silva de Cifuentes en los concejos de Atienza y Medinaceli (1431-1779)», Revista de historia moderna: anales de la Universidad de Alicante, 24, 2006, pp. 395-436.

CODOIN, Colección de documentos inéditos para la historia de España, Madrid, Imprenta de la viuda de Calero, 1869, vol. LIV.

Crivellari, Daniele, Marcas autoriales de segmentación en las comedias autógrafas de Lope de Vega: análisis y estudio, Kassel, Reichenberger, 2013a.

Crivellari, Daniele, «Dal manoscritto alla scena: El piadoso aragonés di Lope de Vega», Testi e linguaggi, 7, 2013b, pp. 63-75.

Ferrer Valls, Teresa, «Lope de Vega y la dramatización de la materia genealógica (II): lecturas de la historia», en La teatralización de la historia en el Siglo de Oro Español, Actas del III Coloquio del Aula-Biblioteca Mira de Amescua, eds. R. Castilla Pérez y M. González Dengra, Granada, Universidad de Granada, 2001, pp. 13-51.

Ferrer Valls, Teresa, "Actores del siglo xvir: los hermanos Valenciano y Juan Jerónimo Almella», Scriptura, 17, 2002, pp. 133-160.

Ferrer Valls, Teresa, «Teatro y mecenazgo en el Siglo de Oro: Lope de Vega y el Duque de Sessa», en Mecenazgo y Humanidades en tiempos de Lastanosa: Homenaje a Domingo Ynduráin, ed.Aurora G. Egido Martínez y José E. Laplana Gil, Zaragoza, Instituto de Estudios Altoaragonenses, 2008, pp. 113-134.

Ferrer VAlls, Teresa, «Lope y la creación de héroes contemporáneos: La nueva victoria de don Gonzalo de Córdoba y La nueva victoria del marqués de Santa Cruz», Anuario Lope de Vega. Texto, literatura, cultura, XVIII, 2012, pp. 40-62.

Labrador Arroyo, Félix, La casa real portuguesa de Felipe II y Felipe III: la articulación del reino a través de la integración de las élites del poder (1580-1621), Tesis doctoral, Madrid, Universidad Autónoma de Madrid, 2006.

Menéndez Pelayo, Marcelino, Estudios sobre el teatro de Lope de Vega, ed. Enrique Sánchez Pérez, Santander, Aldus, 1949, vol.VI.

Presotto, Marco, «La mayor virtud de un rey. Note sul processo compositivo di una commedia di Lope», Cultura Neolatina, LIX, 3-4, 1999, pp. 349-371.

Presotto, Marco, Le commedie autografe di Lope de Vega. Catalogo e studio, Kassel, Reichenberger, 2000.

Rodao García, Florentino, Españoles en Siam (1540-1939). Una aportación al estudio de la presencia hispana en Asia, Madrid, Centro Superior de Investigaciones Científicas, 1997.

Sierra Matute, Víctor, «Historia del Códice Daza», Manuscrt. Cao, 10, 2011.

Vega, Lope de, ¿De cuándo acá nos vino?, ed. Delia Gavela García, Kassel, Reichenberger, 2008. 
Vega, Lope de, La dama boba, ed. Marco Presotto, en Comedias de Lope de Vega. Parte IX, Lérida, Milenio / Universidad Autónoma de Barcelona, 2007, pp. 1293-1466.

Vega, Lope de, Rimas II [segunda parte], ed. Felipe B. Pedraza Jiménez, Madrid, Universidad de Castilla-La Mancha / Servicio de Publicaciones, 1994.

UsandizAga, Guillem, La representación de la historia contemporánea en el teatro de Lope de Vega, Madrid / Frankfurt, Iberoamericana / Vervuert, 2014.

Zıомек, Henryk, A Paleographic Edition of Lope de Vega's Autograph Play «La nueua victoria de d. Gonzalo de Cordona», New York, Hispanic Institute in the United States, 1962. 


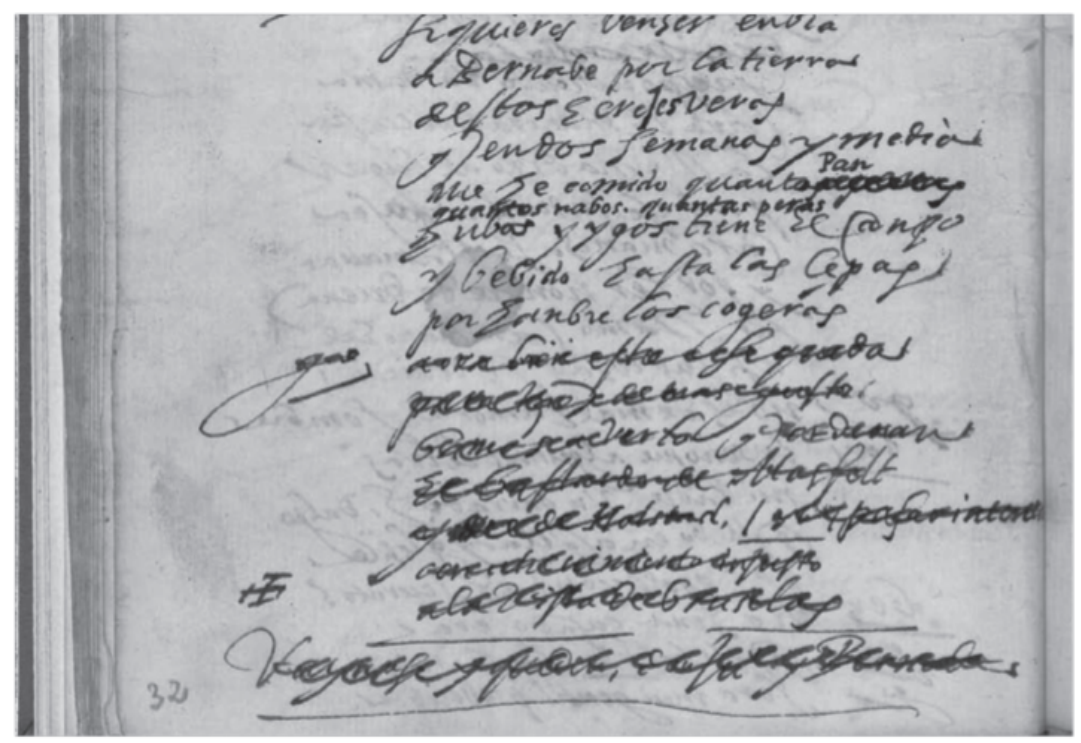

Imagen 1 (fol. 15v, acto I).

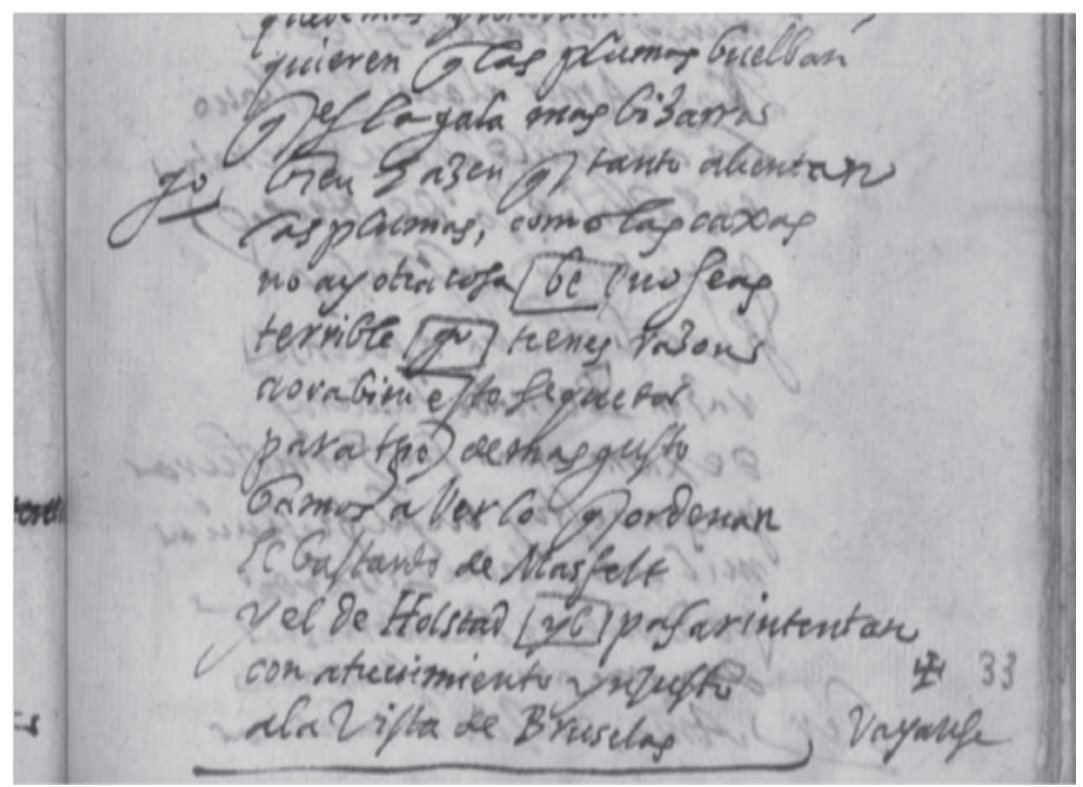

Imagen 2 (fol. 16r, acto I). 


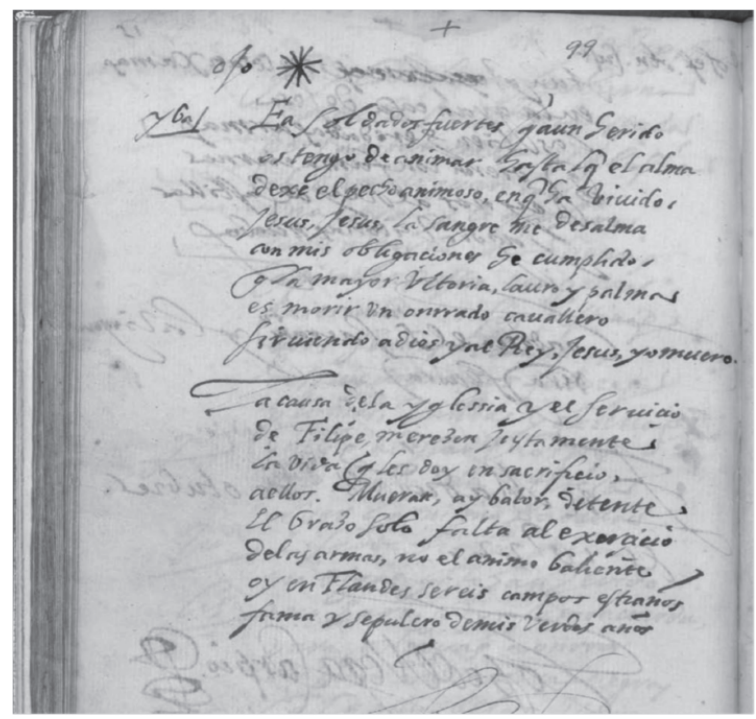

Imagen 3 (fol. 15v, acto III).

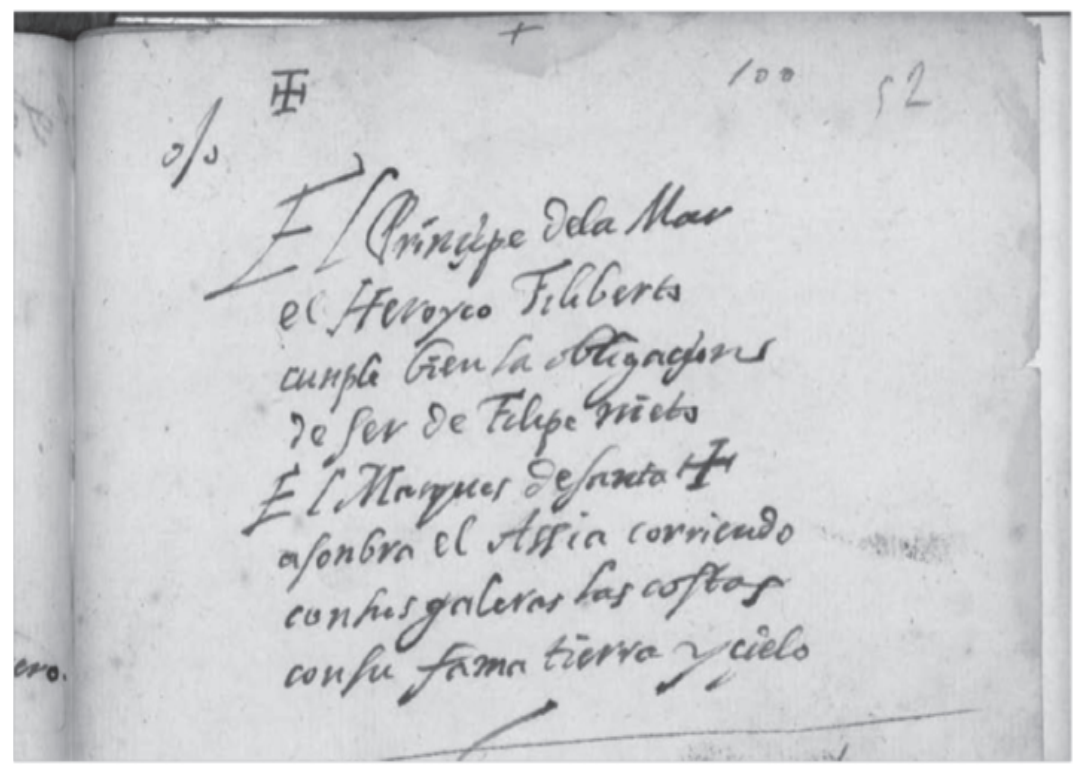

Imagen 4 (fol. 16r, acto III). 


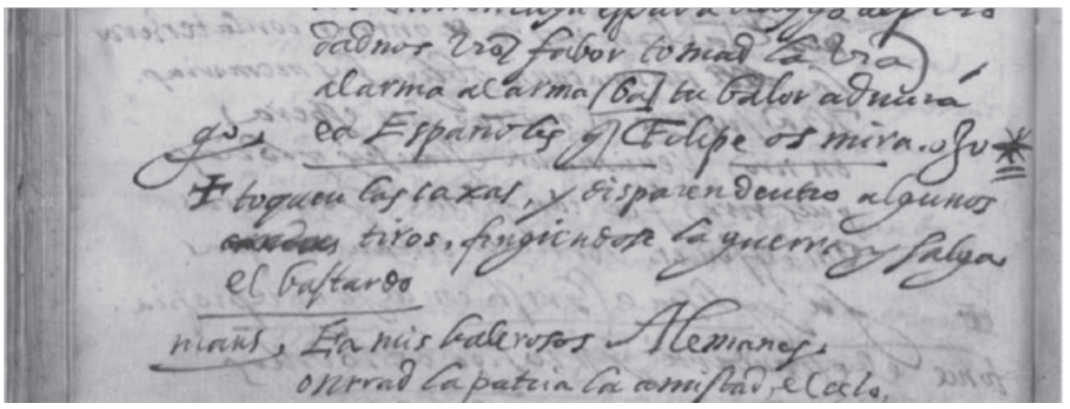

Imagen 5 (fol. $5 \mathrm{v}$, acto III).

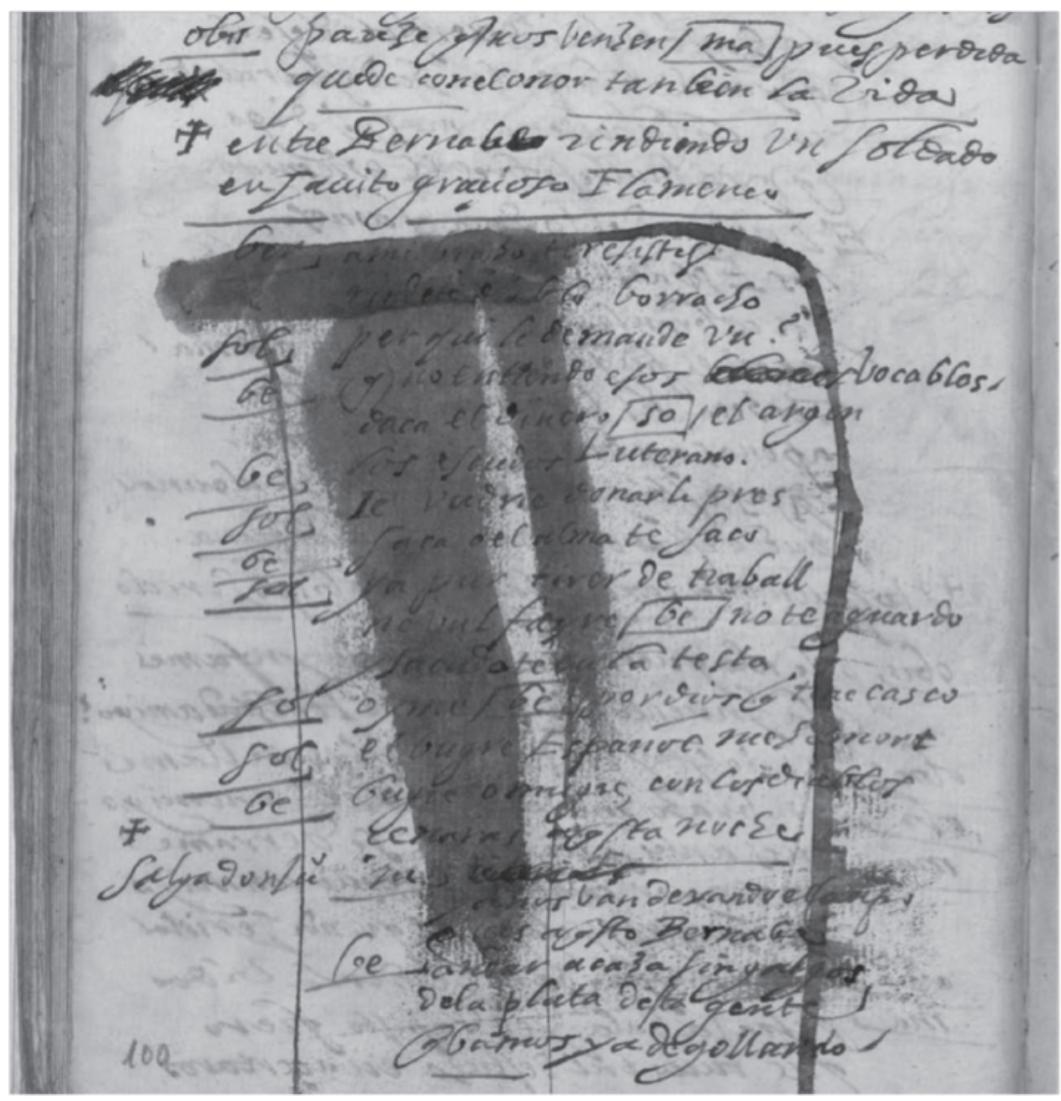

Imagen 6 (fol. 6v, acto III). 